\title{
Novas tendências do mercado de trabalho ${ }^{1}$
}

\section{Introdução}

O presente texto tem por objetivo, nas condições de ruptura da relação salarial fordista que está acompanhada por uma elevação brusca do desemprego, tentar refletir sobre algumas das novas características que esta relação assume. A partir de então, começam a emergir diferentes variantes de configurações "pós-fordistas" da relação salarial e da relação de emprego. A análise proposta refere-se somente aos grandes países capitalistas completamente desenvolvidos, que conheceram um período longo do estabelecimento e afirmação do fordismo, bem como as relações de trabalho e de emprego que lhes são próprias.

Antes de proceder ao exame das tendências atuais, proponho voltar à noção de "relação salarial", introduzindo uma categoria nova - a da "pressão salarial"— bastante útil à reflexão. Em primeiro lugar farei uma caracterização teórica sobre as mutações que hoje conheço da relação salarial. Em seguida esboçarei — baseado na construção de mini-cenários — uma perspectiva sobre algumas grandes tendências atuais.

\section{Pressão salarial, relação salarial, relação de emprego}

É por analogia com os conceitos tirados da teoria da moeda - e especialmente com a noção de "pressão monetária"— que a noção de "pressão salarial" pode ser definida.

Relembramos, para começar, que em teoria monetária a "pressão salarial" designa a necessidade, para as autoridades monetárias, de

Professor

de Ciências Econômicas, Diretor do Centre de Recherche en Economie Industrielle CREI,

Université

Paris 13 
reproduzir a moeda como equivalente das mercadorias, na sua tripla função: de contagem, de intermediária das trocas e de reserva dos valores. Num regime fundado sobre a troca generalizada no mercado, a "pressão monetária", assim definida, constitui uma condição de existência da própria troca, uma exigência absoluta de toda política econômica. Se as autoridades públicas, garantidoras em última instância, não satisfizerem esta pressão, ocorrerá a vinda de crises sistemáticas de grande extensão, das quais uma das expressões mais manifesta é o desenvolvimento de formas agudas de inflação (algumas vezes hiper-inflação), cujos efeitos desagregadores manifestam-se sobre o conjunto da economia e do corpo social.

Por analogia, admite-se que nas sociedades de capitalismo plenamente desenvolvido exista uma pressão salarial, se se coloca a necessidade de reprodução do assalariado para o capital (quer dizer, a relação salarial entendida como a troca da força de trabalho por dinheiro), como modo hegemônico de reprodução dos indivíduos, além da totalidade social que eles constituem e na qual estão inseridos.

A noção de "relação salarial" à qual nos referimos exige, por sua vez, ser melhor definida e detalhada. Nós o faremos caracterizando-a em referência à "relação de trabalho", que é mais englobante, e da qual ela deriva. $\mathrm{O}$ motivo da distinção que nos propomos a realizar aparecerá claramente ao longo dessas notas.

A noção de "relação de trabalho", como sabemos, designa uma realidade extremamente vasta ${ }^{2}$, cuja essência combina e articula, sob um vocábulo único, níveis múltiplos de análise da relação capital-trabalho nas sociedades fundadas sobre o assalariado. Esta definição bastante extensiva é perfeitamente adequada aos níveis macro-econômicos e macro-sociais de análise. Assim, ela se mostra especialmente eficaz e útil, notadamente para caracterizar os regimes de acumulação e de crescimento em períodos históricos longos, a partir dos traços centrais ligados à relação capital-trabalho. Particularmente, esta noção - e as categorias que lhe são associadas — permite colocar em evidência (ou esclarecer sob uma nova luz) certos determinantes e fórmulas-chaves que dizem respeito às condições de obtenção e de divisão dos ganhos de produtividade entre os grandes atores sociais ${ }^{3}$.

Entretanto é forçoso constatar que se a noção macro-econômica conserva seguramente, em seu nível, sua pertinência nesta fase de mutações aceleradas, cada uma das dimensões componentes da "relação de trabalho" possuem evoluções próprias, e estas se desenvolvem segundo modalidades e ritmos diferentes. Nestas condições, torna-se útil construir categorias intermediárias mais elaboradas, permitindo apreciar com maior precisão as evoluções particulares de cada uma das dimensões constitutivas da "relação de trabalho".

Para responder a tal necessidade, propomo-nos aqui definir a categoria da "relação salarial". Deste ponto de vista, a relação salarial, 
repitamos, como um dos componentes que estrutura a relação de trabalho, pode ser definida primeiramente a partir de dois traços essenciais:

a) é uma relação contratual que representa os indivíduos livres numa situação de troca, mesmo se dentro desta relação se manifestem relações assimétricas entre o alugador de sua própria força e aquele que adquire o direito de uso, o que dá à relação salarial características muito particulares e singulares ${ }^{4}$; a arte do gestor da mão-de-obra consiste em conseguir o esforço de maior qualidade e intensidade possível, no tempo durante o qual ele detém o direito de uso $^{5}$ garantido pelo contrato de trabalho, que o liga ao assalariado;

b) é uma relação monetária "direta", que consiste na troca de tempo (de trabalho) por dinheiro, mesmo se o salário que sanciona esta relação obedeça a regras de formação e evolução, em parte determinadas pelas disposições legais, regulamentares ou contratuais (notadamente sob a forma de convenções coletivas) estabelecidas fora da estrita relação "pessoal" e direta, que liga as pessoas contratantes no mercado de trabalho.

Estes dois traços não são suficientes, portanto, para definir a totalidade da relação salarial tal qual ela está afirmada e adiantada nas sociedades salariais plenamente desenvolvidas. Com efeito, nestes tipos de sociedade, como tal relação tornou-se hegemônica, gerou para o capital, considerado no seu conjunto, uma contradição essencial entre reprodução "cotidiana" da força de trabalho e sua reprodução "de longo prazo". É que a reprodução da relação salarial supõe que o modo "troca de tempo de trabalho por dinheiro" permite a reprodução dos indivíduos sociais na totalidade que eles representam, e segundo procedimentos que permitem uma reprodução "intergeneracional" dos assalariados. Na falta disto, se a relação monetária "direta" não pode possibilitar que isso aconteça, torna-se necessário uma relação monetária "complementar" (designada sob o nome "relação de transferência ligada"), assegurando diferentes modalidades de complemento e de "sutura" que a relação salarial direta, na sua própria ordem, não pode realizar: trocas entre pessoas "livres", sancionadas em um contrato.

Praticamente é isto que acontece, quando as "bases domésticas", a partir das quais se fazia uma parte essencial da reprodução da força de trabalho social, encontram-se destruídas ou têm seu papel diminuído ${ }^{7}$. Desde então, tem sido estabelecido o regime do salário. Neste quadro, o essencial da reprodução "cotidiana" foi coberto pelo salário "direto", enquanto que para enfrentar as dimensões da reprodução "longa", foi necessário colocar em prática modalidades de transferências monetárias aos assalariados, distintas do salário direto. A gestão destas transferências então conduziu ao aparecimento dos sistemas pesados e complexos, que sãos os sistemas de Seguridade Social e Previdência. 
Assim, a mutação ocorrida com a relação salarial, ao alterar-se para o regime assalariado, concretizou-se em uma complexificação que se traduz em um regime constituído não mais de uma relação direta (dinheiro por tempo de trabalho), tendo a função de reprodução geral dos salários, mas sim em um sistema de relações distintas umas das outras, ligadas entre si por regras jurídicas que incluem os procedimentos de gestão e da transferência das massas financeiras implicadas na relação salarial. É assim que à relação "individual” de natureza contratual — do tipo troca "direta" do tempo de trabalho por dinheiro - misturou-se e acrescentou uma relação de transferência de rendas monetárias ligadas à relação de troca contratual, mercantil propriamente dita ${ }^{8}$.

Chegando nesse ponto e para resumir a argumentação, vamos colocar que a relação salarial "completa", típica do regime assalariado plenamente estabelecido, liga e associa: 1) uma relação "direta" de troca de trabalho por dinheiro - que designaremos também sob o nome de "relação de emprego",; 2) uma relação de transferência de rendas monetárias "adiadas", ligada à natureza e às características da relação de emprego. Finalmente convém notar que é o conjunto "relação de emprego"+"relação de transferência monetária ligada", que constitui a relação salarial característica e típica do regime assalariado. E é a necessidade de reproduzir esta relação salarial, na sua dupla dimensão, que dá - em cada condição particular — seu conteúdo mais preciso à noção de "pressão salarial" e às contradições particulares que ela enfrenta, através dos vários modos de gestão desta pressão ${ }^{10}$.

\section{Mutações da relação de emprego e da relação salarial}

O ponto importante e que justifica o interesse em pormenorizar as noções sobre "relações de trabalho", relação salarial, é que no período recente, face aos fortes processos de ruptura da relação de emprego e de des-salarização relativa, ${ }^{11}$ assiste-se a movimentos largamente inéditos e em parte "inversos" daqueles que percorreram ascensão do capitalismo como modo hegemônico de produção. Tudo acontece como se neste final de século assistíssemos a um tipo de inversão de tendências: ao invés do processo de extensão e de consolidação da relação salarial, são colocados em prática processos diversos de des-salarização e desagregação da relação salarial, tal como ela se constituiu e se afirmou ao longo de período de hegemonia do fordismo. ${ }^{12}$

Mais precisamente, a ruptura da relação salarial realiza-se por meio de um conjunto de novas formas. Sobre a base de um desemprego mais 
ou menos consolidado ou cíclico, assiste-se a uma série de processos simultâneos, sendo os principais os seguintes: ${ }^{13}$

a) um aumento relativamente forte das relações de emprego "precárias", enfraquecidas ou incompletas - mas que permanecem inseridas e beneficiárias da relação de transferência monetária ligada (ou adiada); trata-se de formas múltiplas de emprego por tempo determinado, ou tempo parcial, bem menos remuneradas que os seus equivalentes de "tempo indeterminado". Na linguagem das teorias de segmentação do mercado de trabalho (Doeringer e Piore, 1971), dir-se-ia que se assiste a um processo de "secundarização dos empregos". Resulta disto o surgimento de uma dupla nova, constituída de uma relação de emprego fraca ou enfraquecida (trabalho precário, contrato por tempo determinado...) e de uma relação de transferência monetária ligada, mantida sob disposições particulares, mas também enfraquecida; estas formas são as mais adotadas pelas empresas, quando se trata de ajustar seus efetivos às variações das demandas e/ou diminuição do custo do trabalho;

b) afirmação de um setor importante, chamado emprego "sem salário", largamente constituído pelo "auto-emprego"; este setor recobre diferentes tipos de emprego, criados sob forma de micro-empresas individuais, oferta/prestação de serviços ${ }^{14}$ etc., permitindo a empreendedores procurar uma renda fora da relação salarial clássica; esta relação de auto-emprego tem por traço marcante o fato de — salvo exceção — não permitir o acesso à relação monetária de transferência ligada, típica do assalariado, senão sob a condição de contribuições voluntárias, para as quais as opções abertas aos trabalhadores "independentes" se assemelham às formas de seguro privado, e para as quais os níveis de garantia em geral são fracos;

c) crescimento relativo do trabalho informal: constituem práticas (desejadas ou impostas pelos agentes), visando procurar renda monetária fora das normas e das regras que regem o mercado de trabalho; estas práticas desenvolvem-se fora da relação de emprego, em substituição ou sob proteção da relação de transferência monetária, quando ela existe, e pode ser prolongada; não é raro que elas incluam também relações em espécie, troca de tempo de trabalho por tempo de trabalho, visando assegurar os elementos da reprodução dos indivíduos ou das famílias, fora das relações monetárias.

Estas tendências, contemporâneas de um forte crescimento do desemprego e de sua manutenção em níveis altos, têm chegado assim à desagregação mais ou menos avançada e pronunciada da capacidade de reprodução dos assalariados por meio do par clássico: "salário direto + salário de transferência adiada". Elas marcam assim a entrada num tipo de "crise sistêmica" do regime assalariado, tornando segmentos importantes da 
população ativa e inativa privados dos meios que asseguram sua reprodução pelo viés das relações clássicas do assalariado.

Nestas condições, e por meio da iniciativa do poder público, assistiuse à emergência e afirmação de relações de "substituição" ou de "sutura" sobre a relação de emprego e sobre a relação de transferência adiada, que se tornaram incapazes de satisfazer por elas mesmas a pressão sistêmica de reprodução do regime assalariado. Fundamentalmente estas novas relações desenvolvem-se com a crise do fordismo e orientam-se (sob formas que podem variar grandemente) em duas direções-chave:

a) afirmação e reforço considerável de uma "relação de formação", como substituto e "sutura" à relação de emprego deficitário (enfraquecido). Em numerosos casos e de maneira notória, a colocação em formação profissional visa somente a possibilitar uma renda aos beneficiários, permitindo-lhes um acesso a meios de sobrevivência temporários; em outros casos, esta relação do circuito de colocação em formação consiste em um tipo de "desafio" sobre a validação a posteriori da formação dispensada, validação que se torna efetiva somente se o mercado sanciona a formação dispensada por meio da admissão (ou contratação), permitindo, assim, o acesso à relação de emprego verdadeira. Uma característica importante da relação de formação, é que ela mantém a existência da relação de transferência ligada, o que lhe confere alguns atributos essenciais da relação de emprego verdadeira; esta relação de "formação", cujo estabelecimento é mantido pela presença de transferências públicas às empresas (ou às instituições especializadas) que nele se engajam, é bastante privilegiada por facilitar a inserção dos "jovens" ou a reinserção, no mercado de trabalho, de pessoas cuja empregabilidade foi erodida (caso notadamente dos desempregados de longo prazo). Na prática esta relação se desenvolve sob duas formas essenciais: 1) na empresa, o que permite aos empregadores abaixar fortemente o custo do trabalho; 2) fora da empresa, nas instituições credenciadas, o que suscitou a constituição de um vasto mercado da “formação". Um número imenso de desempregados, mas que como tais não são levados em conta nas estatísticas de desemprego, de fato, circulam assim de estágios em estágios;

b) estabelecimento de uma relação de transferência monetária "não ligada", concebida como substituto deliberado e voluntário à relação de emprego quebrada (rompida). Trata-se aqui de fórmulas de "transferências" monetárias construídas em referência, mais ou menos explícita, à noção de "renda universal mínima garantida" prometida por alguns, e que toma a forma de transferências assistenciais de naturezas diferentes ( na França, o centro destes dispositivos é constituído pela RMI: Renda Mínima de Inserção...). É de se notar, no que diz respeito 
à RMI, que a sua colocação em prática envolve numerosas precauções, inclusive sobre um plano estritamente semântico, porque também a renda mínima destinada aos sem trabalho é chamada de "inserção", guardando sobre o plano simbólico uma ligação — de fato largamente fictícia com a relação rompida e, frequentemente, desde muito tempo, inexistente. Esta nova prática enfrenta problemas nascidos pela entrada para um número considerável de pessoas - em zonas de "fim de direitos", no caso, o sistema de "transferências ligadas" no salário adiado, que foi concebido na época do fordismo para situações de desemprego relativamente curtas. Os fenômenos de "histerese" que acompanharam a consolidação de um desemprego de massa forçaram a colocação em prática destas relações de um tipo totalmente novo (baseadas sobre a "renda sem trabalho"), frente às quais o capital sempre opunha a mais viva e determinada das resistências. Mesmo se as modalidades da colocação em prática deste princípio associam fortes condições à liberação da renda, dando assim uma realidade à idéia de que é possível obter "renda sem trabalho", esta tendência expressa uma regressão espetacular em relação às ambições e aos objetivos de Spinhamland. Ela é um outro indicador, na nossa opinião o maior, da crise sistêmica profunda que afeta o regime do assalariado e das inovações institucionais que tiveram que ser colocadas em pauta, para enfrentar as novas contradições que afetam a gestão da "pressão salarial".

Como podemos ver, é uma relação salarial profundamente metamorfoseada, largamente heterogênea e "balcanizada"15, marcada em seu centro por um duplo processo de des-salarização e de uma larga secundarização dos empregos assalariados.

\section{Implicações das mutações}

Ao menos três séries de conseqüências podem ser tiradas dos desenvolvimentos antecedentes.

\subsection{Sobre a composição atual do assalariado}

A primeira das consequiências importantes que resultam destas mutações diz respeito ao surgimento de uma série de figuras novas - e fortemente diferenciadas - ocupando doravante o espaço do assalariado, se ele for considerado no conjunto das formas que constituem a sua heterogeneidade fundamental.

A situação aqui é altamente paradoxal. Porque ao mesmo tempo em que se multiplicam, se estendem e se difundem em profundidade no tecido produtivo as diferentes variantes destas formas "enfraquecidas" 
da relação de emprego características do fordismo, a revolução tecnológica

e organizacional em curso leva também à formação de núcleos estáveis de trabalhadores altamente qualificados e polivalentes, beneficiadores, de fato, senão de direito, de uma alta proteção, tanto em termos de status quanto de contrapartidas salariais.

É que na verdade o mercado mundial, abrindo novos graus na integração e interconexão de diferentes espaços nacionais (ou continentais), criou dentro das formas fordianas clássicas da "competitividade custo", que muitas vezes (com a penetração no mercado mundial dos países com custo salarial baixo ou muito abaixo) ainda estão acirradas e fortalecidas, a emergência de formas renovadas da "competitividade hors-coût", onde a inovação, a qualidade dos produtos, a capacidade de diferenciá-los e adaptá-los ao gosto do público e de entregá-los rapidamente constituem os determinantes-chave da competição entre firmas ou nações ${ }^{16}$. É essencialmente para enfrentar estes tipos de mercado, voláteis e exigentes, que foram promovidas estas novas figuras de trabalhadores polivalentes, extremamente competentes, e que possuem grandes capacidades de iniciativa e adaptação frente a situações rapidamente mutáveis.

Daí também o paradoxo indicado: a crise do fordismo ao mesmo tempo que provocou uma busca em massa de rebaixamento dos custos do trabalho, notadamente pelo enfraquecimento das relações de emprego e das relações salariais "garantidas", faz surgir a exigência de trabalhadores mais qualificados, competentes e polivalentes, o que evidentemente é largamente contraditório com a política de rebaixamento daqueles custos, e que se apresenta como a principal das tendências em curso. ${ }^{17}$

Resulta em todos os casos destas séries de mutações, que o espaço do trabalho é doravante motivado por um jogo de comportamentos e de interesses em parte inéditos, em relação àqueles que redundavam da colocação em pauta das grandes regularidades sociais e econômicas fordianas. Nas duas extremidades de um assalariado implodido, os "excluídos", os assalariados, os "marginalizados" ou "banalizados", que são, de um lado, as vítimas das mudanças em curso, coexistem com as figuras novas dos "fabricantes", dos "tecnólogos" ou "gestores" que, ao contrário, reúnem em seus perfis as características essenciais dos mercados de trabalho "primários". ${ }^{18}$

\subsection{Formas inéditas com status e durabilidade imprevisíveis}

Se olharmos de longe a estrita descrição das tendências observáveis na multiplicidade de suas formas, para centrarmos no essencial, é doravante evidente que a crise e a ruptura das relações fordianas canônicas, 
provocando mutações drásticas na relação de emprego, têm também conduzido a uma mutação substancial da relação salarial fordiana tradicional. Em termos teóricos, tudo se passa como se a "pressão salarial" nascida do regime assalariado não se mantivesse mais e fosse reproduzida somente através da multiplicação da geração de formas de empregos enfraquecidas, ao mesmo tempo que, por meio da aparição de formas da "renda sem trabalho", perfilam-se formas inéditas de "sutura" das rupturas abertas pela crise do fordismo. Fazendo isto o capitalismo aparece como devendo renunciar (foi assim a título provisório) a certos fundamentos, os mais permanentes, sobre os quais havia construído as suas forças essenciais em matéria de disciplina industrial. Isso seria um evento histórico maior, correspondente ao que poderíamos designar como "O Fim da Grande Promessa", com a qual o capitalismo parecia comprometer-se ao assumir o desafio de assegurar, por seus próprios meios (trocas de força de trabalho por dinheiro através do regime assalariado), a reprodução dos indivíduos, como da sociedade em seu todo.

O crescimento das formas de "substituição" ou de "sutura" que nós relembramos, se permitem, por um lado, fechar algumas aberturas mais visíveis causadas pela crise sistêmica do regime assalariado, por outro, levam, a outras esferas ou domínios, às contradições que se pretende enfrentar. É assim que o custo crescente da proteção social conduz, por sua vez, ao rebaixamento mais ou menos pronunciado das diferentes proteções e ao crescimento dos desequilíbrios financeiros, dentro dos dispositivos da Seguridade Social e Previdência (aumento da dívida e de encargos dos juros). Todos estes sinais atestam claramente a inflexão na qual entramos, e as condições muito particulares nas quais está confrontada doravante a crise sistêmica do assalariado e da gestão de sua "pressão salarial".

Neste ponto, entretanto, a questão é que não se sabe se a ruptura da "promessa" é irreversível, ou se o que acontece, consiste apenas em uma reorganização estrutural dos meios e dos suportes pelos quais as exigências mínimas requeridas pela satisfação da "pressão salarial" são e serão (mais ou menos solidamente) realizadas. Tudo leva a pensar, em todos os casos, que nos encaminhamos em direção a trajetórias nacionais fortemente diferentes e contrastantes, correspondendo a conjuntos de formas estruturais muito diferentes e muito desigualmente estáveis e eficientes. ${ }^{19}$ Em outros termos, a questão pode ser formulada para saber se estas formas "enfraquecidas" e as formas de "suturas" que as acompanham dizem respeito somente à transição do fordismo ao pós-fordismo, ou se elas correspondem a formas doravante estruturais do pós-fordismo, chamadas a constituir um novo modo, a longo prazo, da gestão da pressão salarial. Neste caso a sustentabilidade deste modo de gestão deverá ser questionada. 


\subsection{As configurações "pós-fordianas" da relação de trabalho: o papel chave do poder na redefinição das regras do jogo}

Frente à multiplicidade de direções que tomam as relações de emprego e de trabalho na virada do século, impõe-se a necessidade de dispor de novas categorias, mais precisas e melhor adaptadas, que permitam compreender o que está em curso; prévia indispensável para poder pretender agir, neste caso, sobre a direção das mutações.

Deste ponto de vista, e numa perspectiva de avaliar melhor as fortes tendências no que diz respeito ao mercado de trabalho e do emprego, colocaremos que nenhuma prospecção séria pode ser feita, a não ser dando todo o espaço a algumas determinações chaves, chamadas a desempenhar, neste processo, um papel motor.

A longo e médio prazo as mudanças que estão se formando não obedecem a um princípio estocástico e aleatório. Só sobreviverão e impor-se-ão aquelas que puderem encontrar uma coerência "sistêmica" mínima. Mesmo estas mudanças, supondo-se que elas atinjam uma forma relativamente estabilizada, não são e não serão igualmente eficientes em sua capacidade de enfrentar as novas pressões da competitividade, que não são senão outra expressão da própria "pressão salarial" ${ }^{20}$. Deste ponto de vista, a história tem em abundância trajetórias nacionais que levaram países ao declínio ou a "círculos viciosos" duráveis.

Também é para nós uma hipótese-chave, que o poder público em sua dupla função de regulador e codificador da relação salarial, de um lado, e de gestor e "garantidor em última instância" da pressão salarial, do outro ${ }^{21}$, é levado a representar um papel determinante, tanto na natureza como na direção das diferentes mudanças em gestação. Devo aqui relembrar e frisar que quaisquer que sejam as margens de ação que lhes são deixadas ou que conseguirem criar — os atores "locais" agem somente dentro das regras do jogo que lhes são dadas. Neste período de ruptura das antigas regularidades e de emergência de práticas largamente renovadas ou inéditas, mais que nunca a natureza das regras que são (ou serão) colocadas pelo regulador e regulamentador terão um peso decisivo.

Ao menos dois pontos aparecem e constituem, em nossa opinião, os pilares básicos da regulação futura do trabalho e do emprego:

a) antes de tudo e levando-se em conta o que foi dito sobre o crescimento relativo das dimensões hors-coût da competitividade, é fato que o princípio de assegurar um certo nível de flexibilidade do aparelho produtivo, envolvendo flexibilidade e mobilidade do trabalho e do emprego, se impõe hoje como uma exigência das economias que devem evoluir em universos estruturalmente instáveis, marcados por ambientes mais 
incertos e mercados mais exigentes; isto sendo colocado, deve ser

lembrado que a mesma procura de "flexibilidade" pode-se obter seguindo protocolos e dispositivos extremamente diferentes em suas modalidades $^{22}$. Enfim, convém levar em conta o fato de que, por diversas vezes, a adaptação às exigências das dimensões hors coût da competitividade (que se apresenta como a grande exigência dos anos futuros) se contrapõe à procura do rebaixamento de custos do trabalho (que se apresenta hoje como o grande meio largamente privilegiado da busca de competitividade);

b) em segundo lugar, sob pena de ruptura geral e de falência sistêmica certa, além da reprodução "cotidiana" do trabalhador individual, é bom que se consiga a reprodução de conjunto e de longo prazo (inter-generacional). Convém então observar que as medidas que visam rebaixar o custo do trabalho para as empresas, através de um conjunto de práticas que nós enumeramos, podem apresentar dificuldades suplementares criadas com o objetivo de satisfazer à pressão salarial sistêmica, transferindo, a quem garante em última instância a reprodução (o poder público e suas agências encarregadas da gestão dos sistemas de seguridade social e previdência), os custos que eles não poderão suportar por muito tempo ${ }^{23}$. Em outros termos, a situação que se pode produzir é a de que aquilo que o poder público faz de um lado - favorecer, pela sua regulamentação, o desenvolvimento de práticas, permitindo rebaixar o custo do trabalho - não consiste em nada mais que multiplicar, de outro, suas próprias dificuldades em assegurar a reprodução da "pressão salarial".

Um caminho muito estreito se desenha aqui, e evidentemente a satisfação destas exigências pode dar lugar a formas "nacionais" e a tipos de relação de trabalho "pós-fordianas" claramente contrastantes e variados.

Por todas estas razões, pareceu-nos útil, sobre a base de fatos fortemente estilizados, propor, para concluir, dois cenários de base, que têm sobretudo valor de referência, para melhor compreender as tendências em curso e as pressões por coerência, que a adaptação a estas tendências fazem surgir.

\section{Perspectivas de evolução: dois cenários}

Os dois grandes cenários aqui propostos são construídos sobre um mesmo jogo cruzado de hipóteses. Estas são relativas às arbitragens entre dimensões custo e hor s coût da competitividade, de um lado, e a reprodução cotidiana e pressão salarial, de outro. Estas duas séries de contradição, que como veremos mantêm umas com as outras relações íntimas, estão no centro das evoluções em curso. 
Por conseguinte e por razões já evocadas, estes cenários colocam deliberadamente ênfase sobre o papel que pode assumir o poder público, como regulamentador e codificador da relação de trabalho.

Frisemos que os dois cenários são fortemente contrastados. Utilizando o método de fatos estilizados (eles "estilizam" as evoluções observáveis nos países existentes), visam fazer emergir categorias e tipos de problemas - e as maneiras de enfrentá-los — na gestão da pressão salarial, na época de crise.

\subsection{Desregulamentação e flexibilidade externa: a variante americana}

Este cenário, que consiste essencialmente na colocação de forma coerente e sistemática das tendências observadas na desagregação da relação "clássica" de trabalho, descrita nos pontos 2 e 3, reveste-se das seguintes características:

a) o mercado de trabalho (dentro das firmas, como na economia no seu todo) caracteriza-se pela multiplicação das formas enfraquecidas de emprego e de trabalho. A legislação do trabalho, bastante permissiva e apoiada sobre medidas de desregulamentação, autoriza ou favorece enormemente o recurso a todas estas formas. As firmas ajustam seus efetivos às variações de pedido, o que permite o rebaixamento dos custos fixos do trabalho, possibilitando que o núcleo de trabalhadores estáveis se beneficie de uma atenção renovada em matéria de status, de formação profissional ou de salário (implementação do salário relacionado ao desempenho, com diversos sistemas de prêmios, motivando a sua individualização). Mesmo sendo decidido fora das práticas contratuais formais, uma espécie de "mercado interno" 24 é preservado, afirmando assim um reforço da dualização do mercado de trabalho e do emprego.

Esta tendência à dualização ainda é reforçada pelo enfraquecimento da legislação concernente ao salário mínimo, ou pelas condições institucionais de reconhecimento dos diplomas, assim como pelo notável crescimento relativo dos empregos de serviços tradicionalmente menos cobertos pelas convenções coletivas.

b) A cobertura social em suas diferentes formas é diminuída (duração e taxa de indenização do desemprego, alongamento da idade da aposentadoria, restrições na cobertura médica...), ao mesmo tempo em que é assegurada a promoção das formas privadas de seguros, permitindo o desengajamento do poder público da gestão de uma parte das transferências sociais e, por isto, de certas dimensões da reprodução longa do salariado.

Como podemos ver, a desregulamentação (notadamente no domínio do trabalho, e principalmente sob a forma de enfraquecimento do sindicalismo e de seus direitos ${ }^{25}$ ) joga aqui um papel chave, favorecendo a emergência 
de novas regras, em contradição mais ou menos aberta com as práticas tradicionais do acordo coletivo (collective bargaining) da época áurea fordiana. A gestão da pressão salarial é buscada através do rebaixamento dos níveis de "transferências" e de garantia, reportando-se aos atores individuais o todo ou uma parte das pressões "longas" de sua própria reprodução (lógica do seguro privado em matéria de saúde e de aposentadoria). Os indivíduos são obrigados a assumir, à medida que podem, uma grande parte das pressões de sua reprodução.

\subsubsection{Vantagens e limites deste cenário}

A vantagem essencial deste tipo de cenário é que se o rebaixamento obtido sobre custos do trabalho é reportado sobre os preços dos produtos, ele se apresenta como favorável aos progressos do custo da competitividade. Se este repasse é somente parcial, ele acaba atrapalhando os lucros que poderiam ser obtidos.

Além do mais, o custo baixo do trabalho e a grande facilidade de admitir e demitir podem-se revelar um fator favorável ao emprego, assim como os lucros estimulados podem servir de base para mais investimento.

Este modelo, ao contrário, não se desenvolve senão que gerando fortes desigualdades suplementares, aumentando mais ainda a precariedade de emprego, a duração efetiva do trabalho, rendas em estagnação ou em diminuição. Contribui ainda para aumento das desigualdades, para substituição de uma lógica de transferências sociais redistributivas por uma lógica de seguro privado.

Enfim, este cenário - mantidas iguais todas as coisas - é pouco favorável à promoção da competitividade hors coût, na medida em que é reduzida ao mínimo a formação de coletivos polivalentes envolvidos na produção.

A longo prazo, este cenário pode-se mostrar muito desfavorável para o país que o pratica, e ainda mais que ele carrega dimensões explosivas: o risco "sistêmico de ruptura" (não reprodução da "pressão salarial") aqui é real. No momento em que o poder público se libera da responsabilidade de cobrir dimensões importantes da reprodução longa, transferindoas aos atores individuais, a sustentabilidade deste cenário é dependente das oportunidades abertas, pela sociedade, aos indivíduos mais despreparados para assumirem sua reprodução pelos meios privados.

\subsubsection{Ilustração}

A título de ilustração podemos citar aqui o modelo inglês da época de Thatcher (que foi por muito tempo o modelo de referência da "flexibilidade externa"), ou o modelo americano (dos Estados Unidos), 
que apresenta a vantagem de ter-se desenvolvido sob duas variantes sucessivas. Do início da década de 70 ao fim dos anos 80, marcados pela era Reagan, o cenário da desregulamentação do trabalho e da dualização desenvolveu-se plenamente. Este período denominado Great U Turn (cf .Harrison e Blastone, 1988) ilustra claramente as tendências à dualização e à balcanização do mercado de trabalho e do emprego, conforme descrito no item 3. Ele também ilustra o crescimento das desigualdades e o prolongamento da duração do trabalho. O modelo mostra as repetidas dificuldades encontradas pela economia americana durante este período nos mercados mundiais (cf. Dertouzos, Lester e Solow, 1989), notadamente em relação ao Japão, e um pouco menos em relação à Alemanha. Estudos econométricos demonstram que, neste período (1970-1990), numerosas vantagens hors-coûts das quais dispunham (no início do período) os Estados Unidos, tornam-se rapidamente decrescentes (cf. Asensio e Mazier, 1991).

Depois do início dos anos 90, o crescimento da renda (assegurado por políticas macro-econômicas apropriadas), no modelo da flexibilidade externa, funciona sob formas diferentes. A mudança essencial está no fato de que o mercado de trabalho é fortemente dinamizado, caracterizado por entradas e saídas aceleradas que se traduzem finalmente em uma taxa de desemprego pouco elevada. Quanto à retomada parcial da competitividade, ela se efetuou mais nos setores de alta tecnologia baseados em P\&D e na aceleração da corrida tecnológica (mobilizando a larga base instalada de P\&D) ${ }^{26}$, do que sobre a qualidade dos produtos e seu crescimento em massa. Nestas áreas (automóveis, material elétrico, construção mecânica...) que, nos últimos anos, não foram marcadas por inovações tecnológicas importantes, e onde a competitividade das firmas ainda se faz sobre a diferenciação e a qualidade, as firmas americanas continuam a enfrentar dificuldades.

Do ponto de vista de sua capacidade em assegurar a reprodução, o modelo de flexibilidade externa parece, no momento, encontrar uma relativa eficácia nos Estados Unidos. Mas esta é fortemente condicionada por uma política macro-econômica, capaz de manter um verdadeiro crescimento. Sendo assim, a despeito do aumento das desigualdades, o forte crescimento permite a reprodução do salariado sob novas formas, sem provocar a explosão de uma crise sistêmica maior. O desafio essencial que deve enfrentar um tal modelo - se ele quiser se reproduzir sem modificações substanciais - consiste em sua capacidade de reconduzir, a longo prazo, altos níveis de crescimento.

A viabilidade e a sustentação deste modelo serão julgadas, então, por sua capacidade de enfrentar a baixa do ciclo dos negócios, quando ela acontecer. 


\subsection{Flexibilidade interna e gestão institucionalizada da mobilidade: a variante européia}

Neste cenário, polar ao precedente, a característica essencial é que o mercado de trabalho está largamente construído sobre a busca da flexibilidade interna. Para enfrentar a imprevisibilidade do mercado, apóiase aqui sobre a construção sistemática de coletivos de trabalho qualificados, polivalentes e capazes de iniciativa e de tomada de decisões. Uma ferramenta-chave da constituição destes coletivos de trabalho repousa sobre um sistema de formação inicial e contínuo eficiente (caso, por exemplo, da formação profissional dual, na Alemanha). $\mathrm{O}$ ajustamento quantitativo se faz então pelo recurso da flexibilidade externa.

As principais características deste cenário são:

a) quanto ao mercado de trabalho, contrariamente ao que caracteriza o primeiro cenário, o salário fica aqui indexado a um conceito de produtividade "social", correspondente a determinado setor ou à economia no seu conjunto, e, por este meio, o poder de compra notadamente para as categorias mais baixas, ou dos assalariados de pequenas empresas, é no mínimo preservado. Neste sentido opera o princípio "keynesiano" da "rigidez à baixa dos salários". Quando prêmios ou recompensas pelas performances são introduzidos, eles privilegiam as dimensões coletivas do esforço, e a atenção é dirigida para a gestão da qualidade dos produtos e as economias em "desperdícios" de todos os tipos, visando compensar os custos do trabalho, que se tornaram elevados pela prática dos mercados internos.

b) Coerente com os princípios que regulam o mercado de trabalho, as garantias possibilitadas pela proteção social não são fundamentalmente retiradas, e são algumas vezes recolocadas para fazer face às novas situações de extrema urgência, criadas pelo desemprego em massa (caso da criação da RMI na França). O objetivo de manter as garantias é procurado geralmente pelas reformas fiscais ${ }^{27} \mathrm{e} /$ ou pelos progressos na gestão dos fluxos financeiros ${ }^{28}$, materiais e tecnológicos ${ }^{29}$, que caracterizam os pesados aparelhos da proteção social.

O motivo destas inflexões múltiplas é que este cenário, se ele for largamente orientado em direção à exploração das dimensões hors-coûts da competitividade, só pode assegurar sua sustentação, se alguns progressos da competitividade do custo são cumpridos. Também ao mesmo tempo em que é procurada uma moderação salarial ${ }^{30}$, orienta-se em direção a uma melhor gestão de todos os fatores de custos, não só os ligados ao trabalho (custo do capital, economias de energias, de matérias primas, melhores taxas e utilização de máquinas e de capacidades instaladas...).

As inovações organizacional e institucional estão assim no centro deste cenário e comanda o seu sucesso. Elas por si só podem garantir de uma vez os progressos da competitividade e os níveis elevados de emprego 
e de salário. Mais particularmente ainda, a redução da duração de trabalho

e a "partilha" dos empregos sob formas variadas (cf. adiante o caso da Holanda, para uma ilustração positiva) são elementos-chave deste cenário, onde a mobilidade no emprego é institucionalmente gerada.

\subsubsection{Vantagens e limites deste cenário}

Os benefícios deste cenário são evidentes se ele for colocado em operação com conseqüência e espírito de continuidade. Em sua forma mais completa, permite a concretização de um tipo de "círculo virtuoso" da qualidade, onde a qualidade do trabalho e das organizações garantem a qualidade dos produtos, e as rendas conseguidas podem ser então reinvestidas no trabalho e na organização. Este mecanismo largamente auto-realizador da sua própria reprodução é perfeitamente ilustrado pela Alemanha nos anos 80 (cf. Streek, 1988 e 1989, assim como o nosso artigo, 1995). Garantindo um alto nível de produtividade, tal tipo de círculo virtuoso da qualidade permite preservar, melhorar os níveis de vida dos assalariados, mantendo ao mesmo tempo a competitividade e o emprego.

Os limites deste cenário estão condicionados por uma longa lista de inovações organizacionais e institucionais (tanto dentro como fora da empresa) exitosas. Ele supõe uma capacidade de fazer evoluir os compromissos sociais, permitindo, a cada momento crítico, uma partilha dos ganhos de produtividade favorável à manutenção do crescimento em um nível satisfatório. O perigo principal é que ele se expõe ao risco, através da institucionalização necessária da relação de emprego e do custo elevado de sua reprodução, favorecendo o aparecimento de uma situação, onde a defesa das aquisições dos insiders se volta contra os pretendentes a entrar no mercado de trabalho, mantendo assim o desemprego em altos níveis e provocando os efeitos de histerese. Se os compromissos apropriados não são encontrados, o mercado de trabalho é aqui pouco dinamizado, no sentido de que as entradas no desemprego não são compensadas por um ritmo suficiente de criação de emprego.

\subsubsection{Ilustração}

As ilustrações deste tipo de modelo devem ser procuradas na Europa continental e notadamente nos países onde existe um sindicalismo forte e garantido, parceiro e ator verdadeiro da contratualização social ${ }^{31}$. A Alemanha e a Holanda fornecem aqui referências muito úteis.

$\mathrm{O}$ interesse de uma referência a estes dois países é que, nos anos 80 e 90, eles conheceram evoluções contrastadas sobre a questão que abordamos, em parte opostas. A Alemanha ilustra uma situação de bloqueio relativo do modelo; a Holanda ilustra, ao contrário, os recursos 
próprios e específicos deste modelo para liberar soluções eficazes e originais. A Alemanha, grande vencedora da década de 80, hoje confronta dificuldades visíveis e tenazes e parece, no momento, ter muitas dificuldades em absorver o forte choque externo que constituiu, com a queda do muro de Berlim, a entrada forçada num processo de reunificação de seu território ${ }^{32}$. Ao contrário, a Holanda, cujas performances na década de 80 eram um tanto quanto medíocres, está hoje no compasso de conseguir uma adaptação tão bem realizada, que aparece como modelo.

Fazendo abstrações dos choques externos ou das contingências, o que podemos guardar destas duas experiências? $?^{33}$

No que diz respeito à Alemanha, o custo muito elevado da reunificação, a importância das transferências efetuadas na região do Leste e seus financiamentos (assumidos num primeiro tempo por empréstimos, o que provocou uma queima das taxas de juros e comprometeu o crescimento e o investimento) fizeram o país entrar num regime de crescimento mais lento, acompanhando-se de um aumento brusco do desemprego. Foi assim que, brutalmente, colocou-se em crise o modelo da década de $80^{34}$, o qual, através de uma política deliberadamente orientada para qualidade, havia permitido à RFA conjugar os mais altos salários do mundo, com a mais curta jornada de trabalho e as mais elevadas exportações. Tudo isto, com um nível de desemprego mantido muito baixo (inferior a $6 \%$ ).

Na situação atual, as vias privilegiadas pelos parceiros são por hora divergentes. O patronato considera possível obter um rebaixamento do custo do trabalho. Os sindicatos, do seu lado, mostram claramente a sua vontade de procurar soluções por meio de novas e importantes reduções da jornada de trabalho (o objetivo das 32 horas semanais está avançado). $\mathrm{O}$ acordo Volkswagen que permitiu preservar milhares de empregos é uma referência bastante avançada, mas se constitui uma incrível exceção.

Atualmente, na ausência de compromisso entre estas duas vias que parecem opostas, o país dá a impressão de se instalar num patamar onde as tensões são mais fortes por causa de um desemprego muito alto (mais ou menos 12\%). Assim a incapacidade de cumprir os compromissos necessários bloqueiam e ameaçam a evolução do país.

Diante desta situação de bloqueio relativo, a Holanda, encontrandose na década de 80 numa situação muito mais deteriorada, soube fazer prova, ao mesmo tempo, de espírito de inovação e de dinamismo.

O cerne da política seguida consistiu em combinar a moderação salarial $^{35}$ e um forte engajamento em direção à redução da jornada de trabalho, a partir de poderosas incitações à escolha do trabalho parcial. É assim que partindo de um nível situado em 1550 horas, em 1983, a duração anual do trabalho gira agora em torno de 1370 horas $^{36}$. Assim, em 1996, mais de um ativo sobre três (37\%), cujos 2/3 são mulheres, 
trabalham em tempo parcial (recorde absoluto para a Europa), o que se

traduz também por uma queda semanal da duração de trabalho de mais ou menos 8 horas por assalariado, em média.

Este movimento só foi possível a partir de um forte compromisso do poder público, apoiado pelos parceiros sociais: $80 \%$ dos setores assinaram acordos de tempo parcial. Três características distinguem e explicam o sucesso da política seguida: a) reconhecimento do direito ao tempo parcial, ao qual o empregador não pode se opor; b) a harmonização dos regimes jurídicos do tempo parcial e do tempo integral; c) a reversibilidade das escolhas, com existência de cláusulas prevendo a volta ao tempo integral, se o assalariado assim o desejar.

Estas disposições permitiram uma redução espetacular do desemprego: a taxa passou de $12 \%$, em 1983, para 6,5, em 1996. Ao mesmo tempo, o crescimento tem-se mantido em níveis satisfatórios e nenhum desequilíbrio ameaça as contas sociais, num país que, tradicionalmente, se beneficia de uma alta proteção.

Aqui então, ao contrário da Alemanha, a máquina contratual tendo sabido funcionar e se adaptar, o modelo se prolonga, evoluindo para enfrentar e, atualmente, superar as dificuldades.

Voluntariamente, escolhemos aqui apresentar modelos muito contrastados e fortemente estilizados. Na prática, é óbvio que as evoluções reais são mais complexas e misturam situações muitas vezes contraditórias. Os cenários propostos não tiveram outro objetivo senão pensar nas linhas possíveis de evolução, que afinal de contas correspondem globalmente a trajetórias nacionais observáveis.

Como pudemos ver claramente por estas notas, o cenário de adaptação baseado na busca da gestão institucionalizada da flexibilidade interna, orientado em direção à competitividade hors-coût, parece-nos tendencialmente mais eficiente, capaz de melhor assegurar as coerências exigidas pela sustentação do regime do salariado e das pressões próprias que ele faz surgir.

É óbvio, como deixamos entender, que os objetivos fixados por tal modelo, que se adapta à crise "pelo alto", não são fáceis de atingir. Mas como dizia o grande estrategista japonês Sun Tze:

"Aquele que não tem objetivos, nunca os atingirá"!... 
1 Texto apresentado no Seminário Internacional "Mobilidade e empregatividade no setor Público", promovido pela ENAP, Brasília, 12/13 maio de 1998.

2 Dentre as diferentes noções de relação de trabalho usadas pelos autores que se aproximam da teoria da regulação, a que mais é citada e levada em conta define a relação de trabalho como: "o conjunto das condições que regem o uso e a reprodução da força de trabalho, englobando a organização do processo de trabalho, mobilidade da força de trabalho, formação e utilização da renda salarial". Cf. R. Boyer (1986).

3 É assim que numa série de trabalhos pôde ser estabelecida a natureza fundamentalmente diferente das convenções coletivas: pôde ser distinguida uma variante americana — na qual o "collective bargaining", sobre a fórmula "ALF+COLA", garante um aumento antecipado do poder de compra dos assalariados — e uma variante japonesa que dá um espaço imenso às avaliações do mérito e aos bônus anuais não-indexados. Estes trabalhos também estabeleceram que estas fórmulas subentendem regimes de acumulação, nos quais as características são notadamente diferentes. Para uma apresentação destes temas ver, por exemplo, nossos livros (1990 e 1991).

4 É importante notar que após ter-se consagrado muitos esforços e energia de negar esta característica particular da mercadoria "força de trabalho" e, por conseguinte, do mercado de trabalho, a teoria neo-clássica desenvolve-se hoje a partir de um retorno espetacular às suas tradicionais hipóteses iniciais nestas áreas. Se formos julgar pela multiplicação dos trabalhos neste ponto, iniciados notadamente por Leibenstein (1982) e Akerloff (1982 e 1984), admite-se pela primeira vez (cf. Solow, 1990) que a mercadoria "trabalho" não é uma mercadoria qualquer, o mesmo podendo ser admitido para o mercado de trabalho - que não pode ser comparado aos outros mercados e tratado com as mesmas ferramentas. Para uma reflexão sobre o significado das novas teorias neo-clássicas do mercado de trabalho e do salário, referimo-nos à revisão crítica detalhada feita por B. Reynaud (1992). Por sinal, numerosas exposições sobre teoria do salário de eficiência — típicas da nova aproximação neo-clássica — estão disponíveis no momento. Sobre este ponto deve-se consultar, por exemplo, A. Perrot (1995).

5 O que é adquirido pelo capital, admite Leibenstein (1982) — que retoma as intuições e as hipóteses marxianas fundamentais — são "unidades de tempo de trabalho"; a intensidade com a qual estas unidades serão utilizadas, afirma ainda Leibenstein, fica sendo uma questão dependente da qualidade das organizações e dos métodos incitativos colocados em prática. Daí a importância do fator "de eficiência X" (organizações e incitações/estímulos), sobre o qual ele insiste fortemente e com razão.

6 Sobre este ponto ver especialmente C. Meillassoux (1976) e, em seguida, S. de Brunhoff (1982). Meillassoux, a partir do que ele designa como "o modelo do Bantustão", mostra como, para uma parte dos assalariados negros da África do Sul, o sistema colocado em prática faz com que o "salário direto" pago aos trabalhadores só cubra a reprodução imediata ("cotidiana"), sendo as despesas "longas" (desemprego, saúde, aposentadoria, criação dos filhos...) transferidas para a comunidade onde os trabalhadores são acolhidos, assim que a relação de emprego é interrompida. Messailloux desenvolve em seguida este quadro de leitura, aplicando-o ao caso da imigração, mostrando como a imigração de "homens, adultos e solteiros" permite aos países receptores dispor de mão-de-obra "barata", estes países não cobrindo uma parte dos gastos de criação e educação dos assalariados, dispensando-se assim de uma parte dos custos 
da "reprodução longa" dos assalariados. S. de Brunhoff, de seu lado, mostra como estas duas dimensões ("curtas" e "longas") da reprodução, assim que tiverem de ser, nas sociedades de capitalismo plenamente desenvolvido, cobertas por meios inteiramente monetários, mobilizam dispositivos complexos e pesados de cobrança e redistribuição, que são na origem os sistemas modernos de Securidade Social e de Welfare.

7 A noção de "base doméstica" caracteriza situações nas quais uma parte da reprodução longa da força de trabalho é assegurada em condições não-mercantis: trabalho doméstico "gratuito" assumido notadamente pelas mulheres em matéria de educação das crianças e da limpeza da casa; muitas vezes também, no quadro da família, cabe cuidar de pessoas idosas após o seu período de atividades e desenvolver trabalho agrícola, visando assegurar uma parte da alimentação, quando a comunidade doméstica não é separada de uma base rural.

8 A afirmação desta novidade se realizará através de um processo extremamente longo e de difícil redefinição e inserção da relação de transferência monetária "indireta" na relação salarial (troca mercantil) propriamente dita. Podemos admitir que este período é também o do fordismo vencedor, que se acompanha, nos países de capitalismo desenvolvido, do progresso contínuo da salarização em massa. Simbolicamente, podemos dizer que Spinhamland (cf. sobre este ponto os desenvolvimentos de Polanyi, 1980), em A Grande Transformação, inaugura na consciência este projeto novo estratégico do capitalismo, que ostenta a ambição e a vocação em assegurar pelos seus próprios meios, através do salariado, a reprodução da totalidade social. Na prática, esta ambição começara a realizar-se só mais tarde, no século XX, com a afirmação da salarização em massa, viabilizada pela progressiva hegemonia do fordismo.

9 É assim que a relação de emprego pode ser definida: a partir do conjunto das disposições relativas ao uso do tempo de trabalho concedido pelo assalariado, em troca do benefício monetário que lhe é dado, em contra-partida, na cessão do uso deste tempo. As disposições particulares ao seu próprio contrato de trabalho, com as que regem estes usos gerais do trabalho, estão codificadas pela Lei ou Acordos Coletivos.

10 É assim que os fortes determinantes da pressão salarial são constituídos por fatores, tais como a demografia e a pirâmide de idades resultante, os níveis de emprego e de desemprego, as taxas de atividades por sexo e faixa etária etc... As disposições institucionais ligadas em torno destes determinantes (obrigações e cotizações, regras de transferência...) formam o "modo de gestão" da pressão salarial.

11 Processos que são contemporâneos da ruptura e da perda de eficácia do regime fordiano de acumulação do capital.

12 Estas considerações valem, como o contexto o indica, para os "grandes países" de capitalismo desenvolvido. Numa visão global, elas devem ser vistas com precisão e de forma balanceada. Com efeito, nos últimos 30 anos, a Ásia e notadamente o Leste da Ásia conheceram um fortíssimo desenvolvimento da salarização. Assim também, de uma maneira mais caótica, vastas zonas da América também conheceram os avanços da salarização. Na virada do século, portanto, e ao menos no que diz respeito ao Leste asiático, o encadeamento das crises (Coréia, Singapura, Indonésia) parece indicar que o desenvolvimento do capitalismo enfrenta sérios limites.

13 As propostas que se seguem retomam certas hipóteses já citadas em meu livro (1990), e sobre as quais me pareceu útil esboçar algumas observações, inserindo-as num contexto teórico diferente do que havia sido exposto antes.

14 No transporte terrestre, por exemplo, é freqüente que os empregadores licenciem ou parem de contratar, preferindo, conforme as necessidades, confiar "missões" de transporte a motoristas "independentes", a quem frequientemente a empresa fornece os caminhões necessários. Na maioria dos casos, esta escolha não coincide com a opinião do motorista, mas é imposta pelo empregador, que se dispensando das obrigações da 
relação assalariada, baixa seus custos fixos do trabalho e transfere ao trabalhador independente os riscos ligados à aleatoriedade das demandas. Este sistema é utilizado doravante em múltiplas áreas de atividade. Ele é um dos elementos que constituem o processo de dessalarização que mencionamos.

15 A expressão "balcanizada" é evidentemente escolhida pela analogia, com o termo utilizado por Kerr (1977), para caracterizar os mercados de trabalho no momento de desenvolvimento da salarização em massa.

16 Sobre este tema da emergência e da afirmação da competitividade hors-cô̂t e de suas exigências em matéria de escolhas organizacionais e de características da força de trabalho, remetemos, para uma apresentação mais precisa dos argumentos, ao nosso livro Made in France (1993).

17 Voltaremos sobre este ponto crucial na elaboração dos cenários, pois eles requerem uma grande parte da inteligência, cf. item 5 .

18 Para a caracterização destas novas figuras produtivas, cf. nosso livro (1990).

19 Cf. item 5 deste texto, onde, sobre a base de trajetórias nacionais diferentes, são propostos cenários de evolução.

20 No prolongamento dos trabalhos efetuados sobre a competitividade de algumas grandes economias nacionais contemporâneas (cf. Made in America, 1989; Made in France, 1993; e Made in Japan, 1998, notadamente), a competitividade é entendida como a capacidade de uma nação (ou de um espaço econômico determinado) em assegurar sua reprodução nas condições de bem-estar melhorado, qualquer que seja o nível de abertura internacional. Sobre este ponto cf. nosso artigo (1997).

21 Este papel de "garantidor em última instância" vem do fato de que finalmente o poder público, e somente ele, deve encarar os déficits das contas sociais que resultam do crescimento dos custos provenientes dos encargos assumidos, em função das pressões da reprodução longa e de certos aspectos da reprodução curta (seguro desemprego, RMI, relação de emprego...).

22 R. Boyer (1985), notadamente, estabeleceu num estudo comparativo internacional a diversidade das vias e meios pelos quais são obtidos diferentes formas de flexibilidade. Ele distinguiu entre duas modalidades fundamentais de adaptação que são a "flexibilidade por baixo" (dominada por modalidades, privilegiando a "flexibilidade externa") e a procura da "flexibilidade pelo alto" (privilegiando a "flexibilidade interna").

23 Notamos aqui que - tudo o mais mantendo-se constante - quanto mais o custo do trabalho "direto" (pago pelas empresas) é diminuído, mais a responsabilidade que é colocada sobre o poder público a título da reprodução "longa" se eleva.

24 Observamos que na maioria dos casos estes "mercados internos" não são mais formalmente negociados e garantidos por convenções coletivas. Eles resultam bem mais do arbítrio gerencial, os gerentes escolhendo dotar certas categorias de trabalhadores julgados estratégicos, de status e de remunerações, comparáveis àquelas que beneficiava os assalariados do mercado interno à época em que estes eram formalmente negociados.

25 Lembramos que R. Reagan (na destruição do Sindicato do Contrôle Aéreo) ou M. Thatcher (que impôs severa limitação do direito de greve por ocasião da greve dos mineiros) se expuseram aos intensos ataques do sindicalismo de seus respectivos países.

26 Cf. sobre este ponto Iansiti e West (1996), e para uma revisão das teses, explicando o retorno das empresas americanas nas tecnologias da informação, cf. Weinstein, O. (1998).

27 É o caso da França, onde para tentar enfrentar os pesados déficits dos regimes sociais, uma reforma tributária está em vigor, visando cobrar uma parte dos encargos que outrora eram inteiramente efetuados sobre os salários. 
28 Na Alemanha, o esforço levou à redução das despesas (notadamente em matéria de saúde), mediante acertos contratuais com os prescritores (médicos, hospitais...) para limitar as despesas comprometidas.

29 Sempre em matéria de saúde pública, freqüentemente, foi favorecido o consumo de medicamentos "genéricos", menos caros do que os seus equivalentes fabricados pelas indústrias farmacêuticas.

30 Tanto sob forma de salário "direto", como sob a forma de rebaixamento dos custos de transferência, conforme vimos anteriormente.

31 Notamos então, e de maneira um pouco paradoxal, que o Japão fornece uma outra variante do mesmo modelo. Aqui também, o modelo está centrado na flexibilidade interna. Esta não se apóia sobre a contratualização formal, mas sobre fórmulas que associam confiança e estímulo. (Para uma comparação dos dois modelos, alemão e japonês, cf. nosso artigo [1995]).

32 Mas convém observar que as escolhas feitas em matéria de reunificação econômica consistiram em transpor ao Leste o modelo completo de relações salariais baseadas sobre a flexibilidade interna, tudo isto em alguns anos. Nestas condições, compreendese que o choque levou um certo tempo para ser absorvido.

33 Experiências semelhantes têm em comum o fato de serem baseadas em moedas fortes, um alto grau de abertura externa, custos do trabalho elevados e uma regulação contratual baseada num sindicalismo poderoso.

34 Para uma análise das contradições que o modelo alemão hoje enfrenta, iremos nos referir a Streeck (1989).

35 O poder de compra do salário médio, por pessoa, progrediu assim de somente $2 \%$, entre 1979 e 1996, contra, por exemplo, 8\% na França, país que mesmo na Europa conheceu uma evolução moderada dos salários.

36 Em comparação, a França - que se situava em 1983 no mesmo nível: 1560 horas anuais — ainda não superou esse patamar (1530 horas em 1996).

\section{Referências bibliográficas}

AKERLOF, G.. (1982), "Labour contracts as partial gift exchange", The Quaterly Journal of Economics, vol. XCII, n. 4.

AKERLOF, G.. (1984), "Gift exchange and efficiency wage theory: Four Views”, American Economic Review, Preecedings, May, v. 74.

Andreasen L., Coriat B., Den Hartog F., Kaplinsky R.. (1995), Europe's Next Step Organisationnal Innovation, Competition and Employment. London: Ed. Frank Cass.

Asensio A., Mazier J.. (1991), "Competitivité, avantages coûts et hors-coûts et spécialisation", Revue d'Economie Industrielle, $n$. 55, ler trimestre.

BOYER, R.. (1986), La théorie de la régulation, une analyse critique. Paris: La Découverte. . (1985), La flexibilité du travail en Europe. Paris: La Découverte.

Brunhoff, S. de. (1982), Etat et Capital. Paris: La Découverte/Maspero.

CORIAT, B.. (1990), L'atelier et le Robot : le fordisme et la production de masse à l'âge de l'électronique. Paris: C. Bourgois/Choix (2ème ed.1995).

. (1991), Penser à l'envers. Paris: Bourgois. 
the Future of Work", in International Contribution to Labor Studies, 5 (pg. 131-151).

. (1997), "The new dimensions of competitiveness: towards au European Approach", in IPTS Review, Special Issue on "Made in Europe".

Coriat B., Taddei D.. (1993), Made in France - L'industrie française dans la compétition mondiale. Paris: Hachette, Ed. Le Livre de Poche.

Dertouzos, M., Lester R., Solow R.M.. (1989), Made in USA - Regaining our Competitive Age, MIT Press (édition française 1991).

Doerionger, P. and Piore, M.. (1971), Internal Labour Markets and Manpower Analysis. Massachussets, DC Heath:Lexington.

Harrison, B., Bluestone, B.. (1988), The Great U-Turn - Corporate Reestructuring and Polarizing of America, New York: Basic Books Inc. Publishers.

IAnsiti M., West J.. (1997), “ Technology Integration: Turning Great Research into Great Products”, in Harvard Business Review, May-June.

Kerr, C.. (1977), The Balkanisation of Labour Market and Other Essays. Berkeley: University of California Press.

Leibenstein, H.. (1982), “The Prisioner's Dilemna and the Invisible Hand, an Analysis of Infra-firm Productivity", American Economic Review, 72, n. 2.

Meillassoux, C.. (1976), Femmes, greniers et capitaux. Paris: Maspero.

Perrot, A.. (1994), Les nouvelles théories du marché du travail. Paris: La Découverte.

Polanyi, K.. (1980), La Grande Transformation. Paris: Gallimard.

Renaud, B.. (1992), Le salaire, la règle et le marché. Paris: C. Bourgois.

Solow, M.. (1990), The labor Market as a Social Institution. Oxford: Basil Blackwell.

Streeck, W.. (1988), "Industrial Relations in West Germany, 1980-1976”, Labour, v. 2, n. 3, Winter.

. (1989), "Skill and the limits of the neoliberalism: the enterprise of the future as a place of learning work", Employment and Society, v. 3, n. 1.

. (1997), "German Capitalism: Does it exist? Can it survive?", New

Political Economy, v.2, n. 2.

WeInsteIn, O.. (1988), “L'Organisation de la R\&D”, Working Paper CREI n. 98-06. (miméo). Univ. Paris 13.

Yochikawa (ed). (1994), Made in Japan. Tokyo: Japan Techno-Economics Society. (tradução inglesa no prelo) 


\section{Novas tendências do mercado de trabalho Benjamin Coriat}

Na ruptura social fordista, o desemprego cresce bruscamente, fazendo surgir configurações variáveis, onde o conceito de pressão salarial passa a designar o complemento monetário indireto, destinado a assegurar a reprodução intergeneracional nas sociedades capitalistas plenamente desenvolvidas. A nova relação salarial compreende a relação de emprego (relação monetária direta) e a pressão salarial (relação monetária indireta). $\mathrm{O}$ aparecimento de relações de trabalho precárias força a pressão salarial a substituir a proteção social em decadência. Dos arranjos em formação, impor-se-ão os que encontrarem uma coerência sistêmica mínima. $\mathrm{O}$ poder público agirá como regulador da relação salarial e garantidor último da pressão salarial, respeitando a flexibilidade do aparelho produtivo e a mobilidade e flexibilidade do trabalho.

$\mathrm{O}$ autor traça trajetórias nacionais baseados em 2 cenários estilizados, que são a variante americana (modelo típico da desregulamentação e flexibilidade externa) e a variante européia (modelo típico da gestão institucionalizada e flexibilidade interna).

\section{Nuevas tendencias en el mercado laboral \\ Benjamin Coriat}

En la ruptura social fordista, el desempleo crece bruscamente, haciendo que surjan configuraciones variables, en que el concepto de presión salarial pasa a designar el complemento monetario indirecto, destinado a asegurar la reproducción entre generaciones en las sociedades capitalistas plenamente desarrolladas. La nueva relación salarial abarca la relación de empleo, una relación monetaria directa, y la presión salarial, una relación monetaria indirecta. El aparecimiento de relaciones de trabajo precarias hace con que la presión salarial sustituya la protección social en decadencia. De los arreglos en formación, se impondrán aquellos que encuentren una coherencia sistémica mínima. El poder público es fundamental como regulador de la relación salarial y garante último de la presión salarial, respetando la flexibilidad del aparato productivo y la movilidad y la flexibilidad del trabajo.

$\mathrm{El}$ autor concibe trayectoria nacionales basadas en dos escenarios estilizados, que son la variante norteamericana (modelo típico de eliminación de la regulación y de flexibilidad externa) y la variante europea (modelo típico de gestión institucionalizada y de flexibilidad interna).

\section{New trends in the labour market \\ Benjamin Coriat}

In the social-fordian rupture, unemployment grows abruptly, bringing about the emergence of variable configurations, in which the concept of salary pressure starts designating the indirect monetary complement, bound to ensure the inter-generational reproduction within fully developed capitalistic societies. The new salary relation then starts encompassing the employment relation - a direct monetary relation, and the salary pressure, an indirect monetary one. The emergence of precarious labour relations impels the salary pressure to replace the decadent social protection. Out of the arising arrangements, those able to find a minimum of systemic coherence shall impose upon others. The public power acts as a regulator of the salary relation and as an ultimate guarantor of salary pressure, respecting the flexibility of the productive apparatus and the mobility and flexibility of labour.

The author draws national trajectories based upon two stylised scenarios which are the American variation (a typical model of deregulation and external flexibility) and the European variation (a typical model of institutionalised management and internal flexibility).
Revista do

Serviço

Público

Ano 49

Número 3

Jul-Set 1998

Professor de Ciências Econômicas, Diretor do Centre de Recherche en Economie Industrielle CREI,

Université

Paris 13 